УДК 160.1

P. MATERNA

\title{
Two Approaches to Philosophically Analyzing Language
}

\author{
Materna Pavel \\ Institute of Philosophy of Academy of Sciences, Czech Republic \\ 11000 Jilská 1 \\ Praha 1, Czech republic \\ e-mail: maternapavel@seznam.cz
}

According to some philosophers we can distinguish two trends in dealing with (especially natural) language. One of them is older and uses explications that simplify the richness of the language, so that the result of its efforts is an artificial image of language not corresponding to its real shape. The more recent trend tries to capture all the richness of the language together with all its irregularities and is represented mainly by Quine's and later Wittgenstein's philosophy. The older trend (I call it analytic group, AG, here) is sometimes criticized as being somehow obsolete while the more recent trend (called here $Q-W$ group, $\mathbf{Q}-\mathbf{W}$, here) is then evaluated as more promising (more 'progressive'). I try to show that $\mathbf{A G}$ is incomparable with $\mathbf{Q}-\mathbf{W}$ because both try to answer distinct questions, solve distinct problems. (A comparison could be realized on the higher level of evaluating the choice of problems itself, which is another topic.)

Keywords: sense, meaning, reference, denotation, explication, abstraction

\section{Motivation}

A characteristic (together with an implicit evaluation) of the two approaches that will be dealt with in this article can be found in [2, p. 240]. (My translation from Czech:)

"Tractatus is '... a document of far-reaching simplifications of talking about 'language', so common among the pioneer generation of analysts. A happy juggling with the words 'language', 'sentence', 'thinking' or 'meaning', not very much taking into account their current (actual) sense and motivated largely by the endeavor to let the results of these 'analyses' fit in (by 
means of analogously stultifying treating the words 'possible', 'necessary' or 'only') is to certain extent characteristic of a part of analytic philosophy up to now.' (Wittgenstein's transient years are) 'a story of waking up from this blissful insanity.' Instead of a perfectly fitting in system of 'language' Wittgenstein 'turned to an incoherent and chaotic landscape of language full of irregularities..."

True, both trends I want to analyze are characterized in this quotation, but this characteristic is surely not 'objective', emotionally neutral: it tries to evaluate both approaches and to show that one of them is passe while the other is 'waking up' from 'blissful insanity'.

One of the key notions enabling the author to write such an evaluation is the notion of simplification. I will show that the author's standpoint is based on a very essential misunderstanding.

\section{Frege's legacy}

In his [10] and articles about nineties, especially in [11] Frege recognized that understanding expressions of a given language has to be explained. He proposed his 'semantic triangle', i.e. the scheme where between the expression and its reference (denotation) there is inserted an abstract object called Sinn (sense, we will use also meaning). The idea was sound: without something like Frege's sense one could not explain why some series of sounds or letters can denote an object, a property, a relation etc. and why distinct expressions can denote one and the same object.

Remember: to explain a fact we have to introduce some abstract notion $(s)$ which explicate (in Carnap's sense) some intuitively understood idea.

Frege was underestimated and ignored by his contemporaries but the development of (not only mathematical) logic, analytic philosophy and logical analysis of (natural) language in 20th century is unthinkable without him. Even the original Warsaw-Lemberg school has been influenced (Ajdukiewicz) and the nominalists from the Vienna Circle had to admit that idea of semantics was attractive [4].

\section{The golden age of semantics}

Frege did not define his sense, he just characterized it as the mode of presentation (see [12, p. 57]), which suggests an important role of the sense but which cannot replace a definition / explication. Therefore Frege himself met a problem with semantics of some subordinate sentences (and tried to solve it, unfortunately accepting contextualism), and in [4] had to solve the 
same problem. This circumstance has led however to a kind of blossoming semantics. David Kaplan writes in his [14, p. 13]:

"During the Golden Age of Pure Semantics we were developing a nice homogenous theory, with language, meanings, and entities of the world each properly segregated and related one to another in rather smooth and comfortable ways. This development probably came to its peak in Carnap's Meaning and Necessity (from 1947).... There is great beauty and power in this theory".

According to Kaplan there were some gaps in this beautiful theory. Kaplan speaks about proper names, demonstratives, quantification into intensional contexts, but we can add some important points:

Carnap himself recognized that his 'method of intensions and extensions' cannot solve some semantic problems ('indirect contexts' - [11], who reacted by 'reference shift' and became a contextualist).

Thus Carnap can be said to have discovered the phenomenon of hyperintensionality (described by [8]). Here we can see the inspiration for Alonzo Church, who began to look for a finer criterion of equivalence of expressions than Carnap's intensional isomorphism: see [7], where Church defines synonymous isomorphism, and Anderson's [1] appraisal of Church's role.

(Church's results can be used when procedural semantics is discovered as a tool of solving problems of contemporary analyses.)

\section{Analytic theories of language}

The development of the analytic theories of language continued in various directions:

Montague's influential school of logical analysis of natural language, based on lambda calculus and presenting particular analyses of a fragment of English. Montague's abstraction works with translations from English to intensional logic and using the standard process of interpreting. See Montague (1970), (1974), [13].

Systems using the idea of possible worlds helped modal logic understand modalities and add to C. I. Lewis-like axioms semantic making it possible to define also empirical modalities due to Kripke's accessibility relations. See [15], [16].

20th century is full of outstanding philosophers and logicians offering their contributions to solving problems first formulated by Frege. We find here so many great names of philosophers and logicians who continued working at 
least partially on the Frege's legacy (Hintikka, Marcus, D. Lewis, Kaplan, not to forget B. Russell essentially inspired by Frege, Woleński, Partee, Schiffer etc. etc.).

This fact can be explained: The problems that were gradually discovered when the Frege's work was finally appraised gave birth to further problems. The endeavor to closer characterize Frege's idea of Sinn led to always new sub-problems.

An important attempt in this respect had it that intensions (as PWintensions) could play this role. This step evoked new problems: the mathematical expressions would not possess meaning? Or: what is denoted by empirical expressions? In what sense can we speak with Cresswell about 'structured meaning'? Is meaning dependent on context?

Among the names of the 'wise (wo)men' working in the 20th century on solving the problems of meaning of the NL expressions one name must be certainly adduced: Pavel Tichý, who founded a semantic system as a hyperintensional system generated by a top-down approach.

Here we adduce Tichý's characteristic of explication because we should be aware of the fact that we do not claim "Meaning is ..." but rather "The optimum explication of meaning is ...". The quotation will also contribute to our main task: showing that the evaluation of the situation concerning the notions of analyzing language, as quoted at the outset of this paper, is based on an essential misunderstanding. The following quotation can be found in [19, p. 194-195].

\footnotetext{
"The purpose of theoretical explication is to represent intuitions in terms of rigorously defined entities. It is to Frege that we owe the insight that the mathematical notion of function is a universal medium of explication not just in mathematics but in general. To explicate a system of intuitive, pretheoretical notions is to assign to them, as surrogates, members of the functional hierarchy over a definite objectual base. Relations between the intuitive notions are then represented by the mathematically rigorous relationships between the functional surrogates".
}

Tichý's characteristic of explication is a concretization of what Carnap said about explication in his [5]. It is clear that every explication has to use abstractions and is therefore a kind of simplification. We will return to this point below. 


\section{Two kinds of criticism}

Whenever some shortcomings or simply not solved problems were detected in the work of analytic philosophers/logicians two kinds of reaction could have been expected:

a) Collegial: A way of removing the shortcomings is proposed so that the explanatory character of the text were preserved.

Examples:

Being dissatisfied by Frege's definition of concept Church redefines concept in [6]. His proposal preserves the realistic character of concept and makes it possible to continue Frege's logical treatment of concepts and of the relation between sense and denotation.

See Church's reaction(s) to Carnap's intensional isomorphism.

When Tichý detects that Frege's 'reference shift' is untenable he defines suppositions de re and de dicto and modifies Frege's semantic triangle.

b) Hostile: The purpose itself of the criticized text is made dubious.

Examples:

Two examples are sufficient here because they essentially influenced the way in which an illusion arose according to which the analytic endeavor to explain some logical puzzles connected with superficial use of language is obsolete and should be replaced by a faithful description of the real use of language.

The first example is the well-known Quine's criticism [17] of Carnap's attempt at defining semantics of natural language in [4]. According to Quine Carnap's proposal is a simplification. His attempt to define the triple meaning, analyticity, synonymy necessarily breaks down because meaning is an obscure notion and language behaves holistically.

Holistic behavior means: "the distinction between the linguistic and the empirical factor (that makes it possible to distinguish between analytic and synthetic sentences) is not significantly traceable into the statements of science taken one to one" [17, 42].

Quine's critique was not oriented as a rectification of Carnap's attempt, unlike Church's critique: it resulted in turning down Carnap's project of explicating semantic notions. Quine replaces this 
project by a pragmatic description of the way language actually behaves (see [18]).

Instead of the 'obscure' notion of meaning in the spirit of Frege's Sinn a behaviorist generalization stimulus meaning is leaving semantics and becomes a naturalistic causal notion. It seems that while Carnap simplifies reality Quine describes it using empirical methods.

The second example is also famous. Wittgenstein's Tractatus was a great attempt at explicating some notions used to explain the way in which language corresponds to the world. This time it was Wittgenstein himself who began to speak about heavy errors in this remarkable book and to abandon any attempt to use abstractions that should explicate used notions to find deep regularities helping to explain linguistic behavior from the viewpoint of its underlying logic. Instead we find now collections of witty observations of particular 'linguistic games', full of interesting ideas and stimuli.

Summarizing, in the light of Quine's refusing analytic methods and later Wittgenstein's shift towards describing 'language games' an impression arose that the analytic approach to studying and analyzing language, which tried to explain some facts connected with using language and relevant from the viewpoint of logic, explicated therefore some more or less unclear notions and used frequently abstraction, is too artificial, and simplifies the complicated world of language use, whereas the philosophers inspired by Quine and the later Wittgenstein, who do not explain the above mentioned facts but describe the way a language is used and for whom generalization is a sufficient kind of abstraction, represent a more 'progressive' form of doing philosophical analyses because they do not need to simplify the complicated reality of language use.

\section{Comments and summarization}

\section{A. Abstraction}

Reality - including the reality of language use is of course complex and chaotic. We can become aware of some features of this reality when using a somehow systematic description and taking into account some generalizations. A more systematic way of detecting some features that are interesting from some relevant viewpoint consists however in abstracting something from something and explicating the notions that arose due to abstracting. 
When we want to explain some phenomenon then multiple abstractions and so multiple simplifications are necessary.

Imagine how such a successful science as physic would develop if it did not systematically use abstraction. It would be probably a boring discipline describing physical phenomena known to everybody.

Nobody will probably criticize physic although it demonstrably simplifies reality. Everybody knows or at least guesses that there would be in practice no physic if simplifications were forbidden. Logical analysis of language is not as 'popular' as physic, so people are tolerated when they comply that it contains so many abstract objects and so simplifications - see the quotation at the outset of this article.

As an illustration of the role of (simplifying) abstraction we adduce a quotation from Tichý [20, p. 183-184], where Tichý answers the question, when Gallileo did mathematics discovering the law of gravity:

"while plotting the values of the function against its arguments Gallileo was not doing mathematics. He was just taking down what was dictated to him by nature. ... But Gallileo not only identified the free-fall function. He also noted that there is a quite a straightforward way of calculating the values of the function from its arguments. Given an argument, all one needs to do is multiply it by two, divide the result by 9,7 , and then take a square root. It was when he made this second discovery, a discovery concerning a complex involving functions and numbers, that he was doing mathematics".

By the way, the simplification given by this calculation is clear: no object will obey the result because the resistance of the given environment has been abstracted from...

Thus abstracting we always simplify but this does not mean that we negate complexity. We can show that as 'simplifying' analysts we know that, necessarily, we simplify but that we know very well that this necessary simplification leads after all to acquisition of new knowledge. In [9] we write:

"The way we understand the enterprise of logical analysis of (natural) language, it is neither eliminative nor reductive, but selective. The analysis selects particular features of language, leaving all the remaining untouched and unscathed. We obviously acknowledge the pragmatic categories of (act of) assertion, language acquisition, communication, speaker's intention, etc. And we acknowledge no less the full range of pragmatic paraphernalia that keep natural language lubricated and running, including non-verbal winks and nods, hints and clues. But while they exist in their own right, they are immaterial to the project of, ideally, isolating all and only logically salient features of (natural) language. So we blot out what is in effect the vast bulk of natural language in order to zoom in on the remaining fragment and blow it, as it were, with a view to studying it in more detail". 


\section{B. Philosophy}

We have suggested the goal of our analytic studies concerning the logical character of some abstract complexes underlying natural language and enabling us to explain the fact that we can clarify the meaning of NL expressions and the deep character of logical laws explained in terms of those complexes. This is in my opinion the task to be gradually fulfilled by our studies and we are convinced that we do something what can be classified with philosophical studies, since it transcends the immediate level of observed facts. Let us speak about the analytic group ( $A G)$.

Now a following question can emerge:

Can we ascribe philosophical character to studies that are worked out in the spirit of Quine and, e.g., the later Wittgenstein $(Q-W)$ ?

There are two possibilities:

I. The work of the Q-W group is essentially a not philosophical work. In this case it is impossible to compare the $Q$ - $W$ group with $\mathrm{AG}$, let alone to claim that the former is somehow more progressive than the latter.

II. The Q-W group is also a philosophically oriented group. Then it is clear that the kind of philosophy applied by it is essentially distinct from that applied by AG. Then, of course, the comparison of both groups is impossible as well.

\section{Ad I.:}

Quine applied philosophy when he criticized Carnap, viz. by using holistic objection. Building up his positive theory of language he created an interesting theory in his [18]. I think however that his theory is based on experience and is restricted to describing phenomena. As a smart description using more generalization than other kinds of abstraction it could be hardly called explication. An empirical description - even be it as good as Quine's - is in my opinion not yet a philosophical analysis. As for Wittgenstein, let him speak:

"Philosophy simply puts everything before us, and neither explains nor deduces anything - Since everything lies open to view there is nothing to explain. For what is hidden, for example, is of no interest to us" [21].

This can be interpreted as either a denial of philosophy or a formulation of philosophy incompatible with the philosophical background of AG. 


\section{Ad II.:}

Well, it would be rather laborious to characterize the philosophy that underlies the views shared by the members of the Q-W group. It will be probably better to mention some points where AG will always dissent with the Q-W people.

The main such point consists in willingness to assume that abstract complexes definable within an explication should be taken seriously: while the members of AG are happy with such complexes the Q-W people warn us against abstract 'commitments'.

By defending the use of abstract complexes (like abstract procedures) members of AG not necessarily speak about 'existence' because if to exist means to be principally spatio-temporally localizable then abstract objects do not exist, as our great Platonist Bernard Bolzano explicitly stated in his [3, p. 224].

Therefore AG people are convinced that explaining some phenomena whose necessary character is admitted (albeit reluctantly) even by the Q$\mathrm{W}$ people can be realized only taking in abstract surrogates for not very clear intuitions. They oppose the inclination to sell this necessity for the necessity of norms, which we can observe in some formulations typical for the members of Q-W. Therewith is connected the well-known reluctance to admit necessities even in logic, as we can read in [17].

The notion of necessity (to be explained by means of using abstract complexes in explications) makes it possible to distinguish empirical (contingent) knowledge from non-empirical knowledge. The borderline is definite (definable) for AG while the Quinean relativization thereof lives in the followers of $\mathrm{Q}-\mathrm{W}$. Thus the AG people warn us against the inclination to accept something like 'absolute empiri(ci)sm', according to which all what can be said about, e.g., language can be said within empirical study pursued, e.g., by linguistic semantics.

Suggesting these differences between $\mathrm{AG}$ and $\mathrm{Q}-\mathrm{W}$ we can state that the problems which have to be solved by $A G$ are distinct from the problems to be solved by $Q-W$. In this sense we can say that the quotation from Beran's book claims nonsense: it tries to compare (and even evaluate) incomparable disciplines.

There is a level on which we perhaps could compare, and maybe that the author of that quotation had in mind this higher level, namely the level where we want to compare and evaluate the choice itself: would you prefer to choose AG, or Q-W? To consider this problem means to compare two comparable approaches if we assume that we want to solve the same 
problems, and claim that one of these choices is better than the other. Yet I tried to show that AG and Q-W actually solve distinct problems. Thus we can say nothing rational to this second interpretation of Beran's 'Conclusion'.

\section{References}

[1] Anderson, C.A. "Alonzo Church's contributions to Philosophy and Intensional Logic", The Bulletin of Symbolic Logic, 1998, vol. 4, no 2. pp. 129-171.

[2] Beran, O. "Středni" Wittgenstein: cesta $k$ fenomenologii a zase zpátky. Červený Kostelec: Nakladatelství Pavel Mervart, 2013. 252 pp.

[3] Bolzano, B. Wissenschaftslehre I. Sulzbach: J.E. v. Seidel, 1837. 730 pp.

[4] Carnap, R. Meaning and Necessity. Chicago: University of Chicago Press, 1947. $231 \mathrm{pp}$.

[5] Carnap, R. Logical foundations of probability. Chicago: University of Chicago Press, 1950. $630 \mathrm{pp}$.

[6] Church, A. Introduction to Mathematical Logic. Princeton: Princeton University Press, 1956. 378 pp.

[7] Church, A. "A Revised Formulation of the Logic of Sense and Denotation. Alternative (1)", Noûs, 1993, vol. 27, no 2, pp. 141-157.

[8] Cresswell, M.J. "Hyperintensional logic ", Studia Logica, 1975, vol. 34, Issue 1, pp. 25-38.

[9] Duží, M., Jespersen, B., Materna, P. Procedural Semantics for Hyperintensional Logic. Foundations and applications of Transparent Intensioanl Logic. Berlin: Springer, 2010. 565 pp.

[10] Frege, G. Die Grundlagen der Arithmetik. Breslau: W. Koebner, 1884. 119 pp.

[11] Frege, G. "Über Sinn und Bedeutung", Zeitschrift für Philosophie und philosophische Kritik, 1892, vol. 100, pp. 25-50.

[12] Geach, P. Black, M. Translations from the Philosophical Writings of Gottlob Frege. Oxford: Basil Blackwell, 1952. 250 pp.

[13] Gamut, L.T.F. Logic, Language, and Meaning, Volume 2: Intensional Logic and Logical Grammar. Chicago: The University of Chicago Press, 1991. 366 pp.

[14] Kaplan, D. "Dthat", Syntax and Semantics, vol. 9, ed. P. Cole. New York: Academic Press, 1990. pp. 212-223. Reprinted in: Demonstratives, ed. by P. Yourgrau. Oxford: Oxford University Press.

[15] Kripke, S. "Semantical considerations on modal logic", Acta Pilosophica Fennica, 1963, vol. 16, pp. 83-94.

[16] Kripke, S. Naming and Necessity. Oxford: Basil Blackwell, 1980. 184 pp.

[17] Quine, W.v.O. From a logical point of view. New York and Evanston: Harper \& Row Publishers INK, 1953, 1961. 184 pp.

[18] Quine, W.v.O. Word and Object. Cambridge: MIT Press, 1960. 264 pp. 
[19] Tichý, P. The Foundations of Frege's Logic. Berlin, New York: De Gruyter, 1988. 303 pp.

[20] Tichý, P. 'Constructions as the subject-matter of mathematic', The Foundational Debate: Complexity and Constructivity in Mathematics and Physics, eds. W. De Pauli-Schimanovich, E. Khler and F. Stadler. Dordrecht, Boston, London, and Vienna: Kluwer, 1995, pp. 175-185.

[21] Wittgenstein, L. Philosophical Investigations. Oxford: Basil Blackwell, 1968. $250 \mathrm{pp}$. 